\title{
Da «pobre vida» à Congregação da Serra de Ossa: génese e institucionalização de uma experiência eremítica (1366-1510)
}

Tese de Doutoramento em História, especialidade em História Medieval, apresentada à Faculdade de Ciências Sociais e Humanas da Universidade Nova de Lisboa, Novembro de 2012. Orientação do Professor Doutor José Mattoso

João Luís Inglês Fontes

\section{(2) OpenEdition}

\section{Journals}

\section{Edição electrónica}

URL: http://journals.openedition.org/medievalista/330

DOI: 10.4000/medievalista.330

ISSN: 1646-740X

\section{Editora}

Instituto de Estudos Medievais - FCSH-UNL

Refêrencia eletrónica

João Luís Inglês Fontes, « Da «pobre vida» à Congregação da Serra de Ossa: génese e

institucionalização de uma experiência eremítica (1366-1510) », Medievalista [Online], 15 | 2014, posto online no dia 01 janeiro 2014, consultado o 22 setembro 2020. URL : http://journals.openedition.org/ medievalista/330 ; DOI : https://doi.org/10.4000/medievalista.330

\section{(c) (7) (8)}

Mediavalista está licenciado com uma Licença Creative Commons - Atribuição-NãoComercial 4.0 Internacional. 
Título: Da «pobre vida» à Congregação da Serra de Ossa: génese e institucionalização de uma experiência eremítica (1366-1510). Tese de Doutoramento em História, especialidade em História Medieval, apresentada à Faculdade de Ciências Sociais e Humanas da Universidade Nova de Lisboa, Novembro de 2012. Orientação do Professor Doutor José Mattoso.

Autor(es): João Luís Inglês Fontes

Universidade: Universidade Nova de Lisboa.

Faculdade e Departamento / Unidade de Investigação: Instituto de Estudos Medievais FCSH-UNL.

Código Postal: 1069-061 LISBOA

Cidade: Lisboa

País: Portugal

Contacto: joaolfontes@hotmail.com

Fonte: Medievalista [Em linha]. №15, (Janeiro - Junho 2014). Dir. José Mattoso. Lisboa:

IEM.

Disponível em: http://www2.fcsh.unl.pt/iem/medievalista/

ISSN: $1646-740 \mathrm{X}$

Data do texto: 29 de Novembro de 2013. 


\title{
Apresentação de Tese/ Thesis Presentation
}

\author{
Da «pobre vida» à Congregação da Serra de Ossa: génese e institucionalização de \\ uma experiência eremítica (1366-1510).
}

Tese de Doutoramento em História, especialidade em História Medieval, apresentada à Faculdade de Ciências Sociais e Humanas da Universidade Nova de Lisboa, Novembro de 2012. Orientação do Professor Doutor José Mattoso.

\section{João Luís Inglês Fontes}

\section{O objecto de estudo}

Não é nova a atenção votada ao fenómeno eremítico por parte da historiografia portuguesa. Com efeito, já em 1972, na sequência do conhecido Congresso sobre o assunto ocorrido em La Mendola, em Itália, uma década antes, José Mattoso publicava, nas páginas da Lusitania Sacra, o seu estudo sobre os «Eremitas Portugueses no século XII». Volvidos quatro anos, o mesmo autor viria a intentar uma primeira síntese sobre os Eremitas da Serra de Ossa, na entrada a eles consagrada no volume III do Dizionario degli Istituti di Perfezione, escrevendo ainda um primeiro esboço, para a mesma obra, da biografia de Mendo Seabra, um dos membros mais eminentes - e melhor documentados - dos primeiro tempos deste movimento eremítico que, em finais do século XVI, viria a constituir-se numa Congregação religiosa, sob a Regra de Santo Agostinho e no quadro da já antiga ordem húngara dos Eremitas de S. Paulo Primeiro Eremita. José Mattoso pudera aproveitar apenas os dados facultados pelos cronistas setecentistas da Congregação, nomeadamente por Fr. Manuel de S. Caetano Damásio, nos dois tomos publicados da Thebaida Portugueza. Maria Ângela Beirante voltaria ao tema em 1985, desta feita com 
o recurso aos diplomas régios relativos aos eremitas alentejanos conservados nos livros de chancelaria. $\mathrm{O}$ artigo, dedicado aos «Eremitérios da pobre vida no Alentejo dos séculos $\mathrm{XIV}-\mathrm{XV}$ », abria novas pistas para o estudo destes grupos que, instalados sobretudo no sul do país, lograriam uma impressionante expansão entre finais do século XIV e o decurso da centúria seguinte. Muitas das abordagens posteriores feitas ao fenómeno basear-se-iam neste estudo para procurarem enquadrar o florescimento eremítico dos séculos finais da Idade Média no contexto mais lato dos novos movimentos de radicalismo e de reforma religiosa que emergem em território português a partir de finais do século XIV ou das estratégias protagonizadas neste âmbito pelos monarcas de Avis ou por outros dignatários, leigos e eclesiásticos, apostados na renovação e ordenamento da vida religiosa.

Um fenómeno conhecido, portanto, mas ainda insuficientemente estudado, com uma base documental muito fragmentária e problemáticas que urgia alargar, face ao aumento exponencial de estudos desenvolvidos sobre o eremitismo noutros quadrantes historiográficos. Mesmo os dados facultados pela cronística da Ordem denunciavam uma clara mistificação das origens, com a projecção nos tempos das primeiras comunidades eremíticas de uma precoce estrutura institucional e de um recuo das mesmas aos séculos iniciais do eremitismo oriental... Os dados já disponíveis deixavam vislumbrar uma outra realidade, marcada pelas tensões típicas da vivência eremítica entre a libertas de quem demandava a solidão do ermo, a pobreza e o abandono do mundo idealmente associados a esta forma de vida, e as exigências de sustento e de ordenamento colocadas pelo aumento e expansão destes grupos e pelas tentativas de controlo sobre os mesmos por parte das autoridades, leigas ou eclesiásticas.

\section{As fontes}

O primeiro problema que se colocava era o da existência de fontes suficientes para o estudo autónomo destas comunidades. Os trabalhos anteriores haviam já denunciado a existência de uma significativa produção documental, por parte dos monarcas portugueses, relativa a estes grupos eremíticos, e as próprias crónicas da Ordem transcreviam ou citavam diversos outros diplomas, oriundos dos cartórios de alguns dos mosteiros que, a partir de finais do 
século XVI, se haviam tornado herdeiros destas primeiras comunidades, após o seu longo processo de institucionalização. A reconstituição do percurso institucional dos eremitérios, a partir das casas monásticas da Congregação cujos cartórios chegariam aos arquivos públicos após a extinção e desamortização liberais, permitiu reencontrar uma parte ainda significativa da produção documental relativa aos primeiros tempos destes grupos, desde que se detecta a sua emergência na documentação escrita até ao assumir de formas mais institucionais e centralizadas de organização e de regulamentação, reconhecidas e aceites por todas as casas.

Foi assim possível recuperar cerca de 1130 documentos para o período entre 1366, data da primeira referência documental a estes eremitas, e 1510, ano que marca a estabilização definitiva da geografia de implantação destes grupos, após a recente elaboração dos seus primeiros textos normativos e a sua estruturação institucional de acordo com o modelo congregacional. Um número certamente surpreendente, face às expectativas iniciais, mas ainda assim enganador.

Com efeito, e como seria expectável, a documentação recenseada mostrava-se desigual no tempo e no seu teor. Desde logo, escassa e lacunar quanto às origens, impossibilitando uma clara percepção da cronologia das primeiras implantações eremíticas, dos seus protagonistas e das suas motivações. Em segundo lugar, só parcialmente reveladora do universo humano destas comunidades: libertos, durante muito tempo, das formas de estruturação típicas da vida monásticas e propositadamente afastados do século para no ermo poderem dedicar-se à oração e aos exercícios ascéticos ou ao trabalho que permitia o seu sustento, raramente toda a comunidade é referida na documentação; em muitos actos, esta faz-se representar por um ou dois dos seus membros e, mesmo estes, insistem em apresentar-se apenas com o seu nome próprio, acompanhado pelo epíteto recorrente de «pobre» ou «da pobre vida». E os eremitas falam pouco de si: adeptos de uma vida pobre, os documentos conservados ou por eles solicitados restringem-se, na sua maioria, aos diplomas que lhes permitiam provar direitos, privilégios ou a posse de terras e bens, entre os que lhes eram doados por benfeitores ou adquiridos em vista a assegurar a sustentação económica das comunidades. 
Ainda assim, foi possível reunir os dados biográficos de 393 eremitas, apresentados na segunda parte da dissertação, de acordo com uma ordenação alfabética a partir do seu nome próprio e, entre os homónimos, de forma cronológica, de acordo com as referências documentais disponíveis. Embora muito desiguais, dada a disparidade de informações disponíveis para cada um, procurou-se recensear os elementos respeitantes à sua origem social e geográfica, redes de relações e percurso dentro da pobre vida. É a dimensão humana deste fenómeno que aqui se traduz, esclarecendo dados que suportam todos os capítulos da primeira parte e abrem caminho para a aferição de eventuais redes de relação, quer com o universo urbano do sul, ainda tão mal conhecido, quer com os diversos círculos do poder (do régio ao nobiliárquico ou das elites locais), quer ainda com aqueles e aquelas que integraram outros movimentos e comunidades religiosas, cujas relações com este universo eremítico aparece por vezes mais visível mas que pode e deve ser ainda aprofundado.

Do mesmo modo, foi possível reunir um conjunto significativo de informações, disponibilizado nos diversos anexos à tese, sobre os eremitérios documentados, a população neles recenseada durante o período em estudo, os seus benfeitores e o universo humano que rodeava estas comunidades (procuradores, lavradores e foreiros, outros servidores).

\section{Uma perspectiva institucional: as problemáticas}

Estas condicionantes encaminharam a análise deste movimento eremítico para uma perspectiva eminentemente institucional, atenta aos dinamismos que motivaram o seu aparecimento, expansão e a adopção gradual de formas de organização interna que confluiriam na opção, em finais do século $\mathrm{XV}$, por um governo centralizado dentro de um modelo congregacional, comum a outros movimentos similares como as observâncias franciscanas, os Jerónimos ou mesmo os Lóios, de matriz mais clerical. As interrogações eram múltiplas: tratava-se de um movimento "nacional", espontâneo, ou enquadrado no contexto de outros movimentos ligados ou influenciados pelos ambientes marcados pela herança dos espirituais franciscanos e pela opção pauperística, que tantos traços comuns apresentavam com estes homens da «pobre vida»? Quem 
protagoniza esta aventura eremítica: seria possível conhecer os seus percursos, o âmbito e evolução do recrutamento destes adeptos da vida eremítica, quer em termos geográficos quer sociais? As comunidades eram sobretudo de extracção laical? E qual o peso do elemento clerical na sua constituição e no seu governo? E, enfim, qual a sua relação com a hierarquia católica, com o poder régio, os concelhos e as restantes ordens? Quem são os seus benfeitores e apoiantes? Como se jogam todos estes factores e relações no percurso que, desde finais do século XIV, leva simultaneamente à expansão destas comunidades e à sua gradual institucionalização?

A opção por este inquérito levou ao desenvolvimento do nosso estudo em torno de três grandes períodos de evolução destas comunidades: partindo dos primeiros indícios da sua emergência documental e do que estes nos possibilitam dizer sobre as possíveis influências que se encontram na génese de tais grupos (1366-1385), estudámos de seguida o período que, em larga medida coincidente com os reinados de D. João I, D. Duarte e a regência e D. Pedro, é sobretudo marcado por uma acentuada expansão destas comunidades, quer em novos locais de implantação quer no número de eremitas que neles residem (1385-1452) para concluirmos com o estudo do período final, marcado por fortes tensões, internas e externas, que, vindas de trás, se agudizam, precipitando a institucionalização do movimento (1452-1510).

\section{A emergência documental (1366-1385)}

Os indícios documentais sobreviventes permitiram, desde logo, detectar a proximidade e influência sobre os eremitas portugueses dos movimentos, marcados pelo pauperismo franciscano, que advogavam uma vivência radical da pobreza, associando a fuga para o ermo a uma vida austera e em pequenas comunidades, muitas vezes sob protecção ou obediência episcopal. Para esta hipótese confluíam a forma de vida e designação adoptada; a presença de eremitas ditos como frades da Ordem Terceira ou da pobre vida; a presença, entre estes primeiros eremitas, de gente oriunda de Castela, da Andaluzia e da Galiza; a memória da circulação precoce em território português de eremitas oriundos dos círculos dos fraticelli italianos (memórias associadas à figura de Fr. Vasco e às origens dos Jerónimos) e, por último, a própria concomitância da 
aprovação pontifícia concedida aos eremitas portugueses (1377-1378) com a outorgada aos Jerónimos castelhanos (1373) e primeiros grupos de observantes franciscanos (1374).

Uma sentença dada por Vasco Domingues, chantre de Braga, na sequência de uma inquirição feita aos eremitas por determinação pontifícia, vinha atestar, quer a impressionantes expansão já então alcançada por estes grupos eremíticos, em larga medida insuspeita face aos fragmentários dados documentais até então disponíveis, quer a definitiva sanção eclesiástica dada à sua forma de vida, provada que era a ortodoxia dos seus adeptos. Contudo, a sentença afirmava ainda a associação, deveras surpreendente, destes eremitas a um presumível projecto pontifício de reforma eclesiástica do Reino, ainda mal conhecido e que viria, em todo o caso, a ser interrompido pelo despoletar do Cisma e pelo agravamento dos conflitos entre os monarcas portugueses e os seus congéneres castelhanos.

Por outro lado, parece clara a autonomização crescente do eremitismo alentejano, que conserva a sua vertente espontânea e popular, que se tornará patente no evoluir do recutamento de novos adeptos e nas resistências que adiarão, face aos movimentos acima citados, a definitiva institucionalização destes grupos eremíticos.

\section{A expansão (1385-1452)}

O advento da nova dinastia de Avis, ultrapassadas as conturbações do final da centúria anterior, marca uma nova fase na vida dos eremitas alentejanos, pautada por um intenso movimento de expansão, entre fundações ligadas à Serra de Ossa e outras implantações eremíticas mais autónomas, ainda que partilhando a mesma forma de vida. No total, trinta e duas novas "fundações" estendem, em apenas algumas décadas, a presença destes eremitas a todo o sul de Portugal, atingindo inclusive o Algarve (uma fundação em Tavira), a Península de Setúbal (eremitérios de Alferrara, Cela Nova ou Barriga e Mendoliva) e mesmo a região a norte do Tejo (eremitérios nos termos de Cascais, Óbidos, Alenquer, Santarém e Figueiró). 
Neste movimento, é clara, desde logo, a protecção facultada aos eremitas por parte dos concelhos do sul e das suas populações, onde se recruta a maioria dos benfeitores das suas comunidades. Mais próximos dos eremitérios, são eles a principal fonte de muitas das terras que os seguidores da pobre vida recebem em doação, em troca da participação nas suas orações e dos benefícios espirituais que daí advinham para si e para os seus familiares. Do mesmo modo, parece evidente o precoce apoio e protecção que lhes são dispensados pelos monarcas, patentes na repetida e constante outorga de privilégios, isenções e cartas de protecção ou mesmo na intervenção directa em ordem a viabilizar algumas das novéis fundações. A mesma política é assumida pelos Infantes, que acolhem e tomam sob a sua tutela alguns eremitérios, nomeadamente os situados em terras da mesa mestral das ordens de Santiago e Avis.

A intervenção régia possibilita ainda a renovação da protecção pontifícia concedida aos eremitas, traduzida, não apenas na outorga de diversos privilégios e isenções (incluindo a isenção do pagamento da dízima, obtida logo em 1397), como na sua submissão à protecção episcopal sem com isso os sujeitar à jurisdição dos respectivos prelados (1407). Do mesmo modo, é graças à generosidade apostólica que os eremitérios poderão erigir no seu interior pequenos oratórios, escolher confessores e clérigos para aí celebrarem os sacramentos e reforçar o número dos seus habitantes, paulatinamente aumentado para 12 (1407) e mais tarde para 20 (1434).

\section{A institucionalização (1452-1510)}

A entrada na segunda metade de Quatrocentos, coincidente com o fim da regência e o assumir definitivo do governo do reino por D. Afonso V, marca uma fase nova na vida destas comunidades, pautada por um crescente intervencionismo régio, por tensões internas resultantes da própria expansão eremítica e do crescimento das suas comunidades e por uma ofensiva crescente por parte de outras ordens, nomeadamente os Lóios e os Jerónimos, com vista à anexação de diversas casas e do respectivo património.

O precipitar de todas estas tensões acontece logo em 1452, com o regimento régio imposto aos eremitas por D. Afonso V, renovado quase sem alterações em 1475, que 
designava três juízes para os feitos dos pobres, impunha diversas directivas disciplinares às suas comunidades e, mesmo afirmando o papel particular da Serra de Ossa sobre as restantes casas, vincava, em última instância, a submissão de todos os eremitas, na sua qualidade de leigos, à jurisdição do monarca e sujeitava à sua aprovação todas as futuras propostas de novas fundações. Por outro lado, Lóios e Jerónimos protagonizariam, com o apoio do monarca, diversas tentativas de anexação de alguns eremitérios: Santa Margarida do Aivado e Rio Morinho, ambos no termo de Évora, pelos Lóios em 1460; a própria Serra de Ossa e Rio Mourinho (termo de Montemor-o-Novo) pelos Jerónimos de Santa Maria do Espinheiro, em 1476 e 1478.

Os eremitas confrontavam-se, a par de todas estas investidas, com diversos problemas disciplinares internos, fruto do crescimento das suas comunidades e, em simultâneo, da ausência de uma normativa clara que regulasse as formas de vigilância sobre as suas casas e o exercício do respectivo governo. O percurso em ordem a uma crescente institucionalização procuraria claramente criar os mecanismos essenciais para a sobrevivência das comunidades e do essencial do seu modo de vida, mesmo com claras cedências a formas mais centralizadas e estruturadas de governo e de regulamentação.

Logo em 1466, os eremitas constituíam-se entre si como uma "Irmandade", assumindo uma solidariedade entre as diversas casas em torno da Serra de Ossa. A algumas decisões de cariz disciplinar então tomadas juntavam-se diversas normas tendentes a impedir os abusos na transmissão do poder sobre os eremitérios ou a alienação dos seus bens, ou a contrariar a imposição unilateral dos juízes impostos aos pobres pelo regimento régio de 1452, exigindo-se para a sua escolha o concurso dos regedores das diversas casas. Em 1478, os eremitas sujeitavam-se à profissão do voto de castidade, imposto por bula pontifícia do ano anterior e, em 1482, já no contexto da procura de uma solução definitiva face às tentativas de anexação de algumas das suas casas pelos Jerónimos e sob pressão do próprio monarca, aceitam constituir-se finalmente como Congregação, com uma estrutura de governo centralizado e uma normativa própria. A um novo provincial, com poder de visitar as restantes casas e de controlar a administração dos respectivos bens, juntava-se agora a limitação de mandatos dos restantes regedores, impeditivo de maiores abusos. Deste capítulo de 1482 deve ter resultado um primeiro texto normativo, hoje desconhecido, que seria completado por um conjunto de «apontamentos» decididos em novo capítulo celebrado em 1488. 
Os escassos e dispersos dados sobre o modo de vida destas comunidades revelam, apesar de toda esta evolução, uma grande fidelidade aos elementos fundamentais que marcavam a opção pela «pobre vida»: a procura do ermo e a salvaguarda da solidão pela cuidada demarcação e vigilância sobre o espaço do eremitério; a aliança entre a oração e o trabalho manual; a manutenção de comunidades pequenas, maioritariamente laicais e com gente humilde ou de posses pouco avultadas, permitindo manter um espaço bem circunscrito para a liturgia e a recusa da actividade pastoral ou da pregação.

\section{COMO CITAR ESTE ARTIGO}

\section{Referência electrónica:}

FONTES, João Luís Inglês - “Apresentação de Tese/ Thesis Presentation. Da «pobre vida» à Congregação da Serra de Ossa: génese e institucionalização de uma experiência eremítica (1366-1510). Tese de Doutoramento em História, especialidade em História Medieval, apresentada à Faculdade de Ciências Sociais e Humanas da Universidade Nova de Lisboa, Novembro de 2012. Orientação do Professor Doutor José Mattoso“. Medievalista [Em linha]. №15, (Janeiro - Junho 2014). [Consultado dd.mm.aaaa]. Disponível em http://www2.fcsh.unl.pt/iem/medievalista/MEDIEVALISTA15/fontes1509.html.

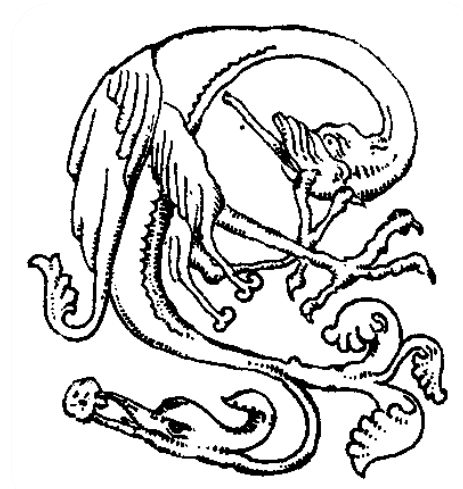

